\title{
The Site Tour
}

\author{
Carol J. Ellick
}

Brochures, booklets, lectures, participation in Archaeology Day events, and site tours are popular forms of public outreach, but when considering the development of an outreach product, certain criteria should be considered. Development of any product presents potential issues related to cost, production, location, advertising, and distribution, but the form of outreach that has the potential for the greatest complications is the site tour. Additionally, the development and execution of site tours includes concerns over funding, safety, and site security. This article addresses these problems by offering tips, scenarios, and creative alternative solutions.

Site tours are popular and provide an opportunity to engage the public directly. The public rarely gets to see "real" archaeology other than on TV, where the realities of archaeological investigations have been condensed into an hour, highlighting what may have taken weeks or months to uncover. Options for site visits are limited to locations that have been set aside for visitation, such as Mesa Verde, where selected sites are open and interpreted, but rarely contain ongoing excavation. At Mesa Verde and other parks, the interpretation is done through signage and tours led by trained interpreters or Park Rangers. Opportunities to see archaeologists in action often occur through ongoing archaeological projects, such as those conducted by cultural resource management (CRM) firms or field schools. Here, tours are usually conducted by a staff archaeologist or crew member with an interest in public archaeology. More than likely, however, these people have not been trained as interpreters. In addition, while a comprehensive plan of work (POW) has been created for the data recovery, a plan for tours probably was not.

\section{DEVELOPING THE NARRATIVE FOR A PLAN OF WORK}

Site tours take place on historic and prehistoric archaeological sites that may be parts of field school experiences, museum programs, and CRM projects. Each situation contains its own set of needs, not all of which can be covered here. For the purpose of this "How-to" article, I use a CRM scenario to illustrate the importance of developing an overall POW and to identify

\section{ABSTRACT}

Archaeological site tours are a common form of public outreach, but are they done as well as possible? Do they convey the information that is intended and are they effective in teaching about archaeology, culture, professionalism, and ethics? Over the years, I've been asked by cultural resource management (CRM) firms and university anthropology department field school directors for information on how to construct and give site tours. In the past, responding to this request meant cobbling together information from various sources and adding commentary. The intent of this article is to bring all of that information, along with 25-plus years of experience, together into one comprehensive narrative with the intention of providing guidance for those who have trepidations about offering site tours as a form of public outreach.

Esfuerzos en educación al público a veces incluyen visitas a sítios arqueológicos, pero nos preguntamos si éstas visitas están organizados para lo maximo éxito. Cómo podremos tener confidencia de que estas visitas están exitosas en el impartir información importante o en el enseñar acerca de la arqueología, la cultura, el profesionalismo, y la ética? Durante los años, companias de manejo de recursos culturales (CRM) y directores de departamentos universitarios antropológicos y escuelas de campo nos han pedido Cómo diseñar y conducir visitas a sítios arqueológicos con responsabilidad. En el pasado, respondiendo a estos pedidos ha sido en forma de información de varias orígenes combinado con comentario personal. Este artículo se intente a unir todos tipos de informaciones con 25 años de experiencia en una narativa comprensiva y dar consejos a profesionales con dudas de la visita a un sítio arqueológico como una forma de educación pública. 
personnel and funding needs. Regardless of funding source, a comparable level of planning should go into creating any sort of public outreach plan.

\section{The CRM Scenario}

You are responding to a Request for Proposals (RFP) to develop a POW for mitigation on a pre-contact site located within the right-of-way of a secondary road on the outskirts of town. The client requires public outreach in the form of archaeological site tours for the general public. On past projects, a crew member gave impromptu explanations of the work to the stray visitor, but most often, you've simply posted notice on the fence that it was unsafe to enter the work area. This is not an option for this situation. What to do and how to do it?

As with other sections in a proposal, you must develop a plan for public outreach. It is as important to maximize the opportunity to engage the public as it is to minimize disruption to the field work. Creating a POW for handling public outreach will help when developing the program and the budget and will demonstrate to the contract officer your abilities to fulfill the public outreach component.

\section{Example Plan of Work}

Continuing with the RFP scenario created above, the following POW was developed to maximize public engagement:

Five tours a day will be offered during the final four weeks of the fieldwork. For security reasons and because it is more interesting to see archaeologists at work rather than just an empty site, the tours will be offered on Monday through Friday. Tours will be 30 minutes long, with 10 minutes for questions and closure, and will be available by registration only. Special tours for school groups, youth organizations, avocational societies, and so forth, will be offered on a case-by-case basis outside of the general public tours.

The tour guide will work with descendant communities and those with affiliation to the site in developing the narrative. Active participation by community members will be sought with the goal of achieving community engagement in the project. The tour guide will spend several days in the field working with the crew to learn about the site, including information about features, diagnostic artifacts, and the types of samples being taken, so that he or she will be able to paint a verbal image for visitors. Props such as site maps, reconstruction drawings, and photos of the features will be produced for use during the tour and a three-panel tabletop display with a guest book will be created for placement at the entrance, under a canopy to the site, where tours will begin. A banner will be hung on the outside fence advertising the tours, and a table banner will be hung skirting the table where the tours start.

At the conclusion of the project, the public outreach specialist will write up the process, list the qualitative and quantitative results, and submit an illustrated report to the client, along with the guest book.
With this level of detail, you can build the actual program, anticipate direct and indirect costs, and develop staffing needs for the four phases: Laying the Groundwork for Public Outreach, Pre-Tour Preparation, Tours, and Follow Up.

\section{LAYING THE GROUNDWORK FOR PUBLIC OUTREACH}

Site tours don't actually begin on-site. In addition to basic questions regarding who will lead the tours, what will be shown, and the more obvious advertising and scheduling concerns, there are three basic issues that should be taken into consideration: funding, safety, and security.

\section{Funding}

Public outreach costs money. In the scenario above, the client has specified that site tours will be included in the project, but there are many instances when public outreach is not included in an RFP. This does not mean that it shouldn't be proposed or included in the budget. Increasing public outreach "starts with changing how archaeologists think about public outreach within the context of CRM" (Ellick 2012). When considering archaeological site tours, or other forms of public outreach not specified in an RFP, discuss the options for including public outreach in the technical and cost proposal with the contract officer. The costs of the program should be in line with the scale of the project, with the budget tied to the plan.

Creative Solution: Talk to Your Client. Get to know your clients and get them comfortable with the full range of public outreach services you can provide. As with consultation, this conversation is ongoing, not just at the moment of proposal submission. Include public outreach as a line item under "Analysis," as you would any other form of "Interpretation." Since no one balks at the idea of hiring a specialist to do macrobotanical analysis, hiring a specialist to analyze the archaeological site, interpret its meaning, and describe it to a lay audience should be a logical outgrowth of the archaeological enterprise. There is no law requiring ceramic analysis, but there is legislation relevant to sharing the results of archaeological work with the public. The National Historic Preservation Act of 1966, as amended, says that what we do is "in the public interest" (54 U.S.C. § 320101), and Standard IV of the Secretary of the Interior's (1983) Standards for Archeological Documentation states that the "results of archaeological documentation are [to be] reported and made available to the Public" (48 FR 44716).

\section{Safety and Accessibility}

Perceptions about safety and accessibility can be one of the greatest challenges to planning a site tour. A lack of parking and heavy vehicular traffic are two of the most common reasons cited for not offering site tours, but there may be other concerns for safety as well. Is there a need for hardhats? Is the site in a less than safe neighborhood, or does it have deep excavation units for which shoring or tapering is required? While the site may not be the best candidate for site tours, that doesn't mean that the information can't be shared with the public. You just have to be more creative. Linked with the concern for safety is the question of insurance. This can be an issue with public outreach events. It 


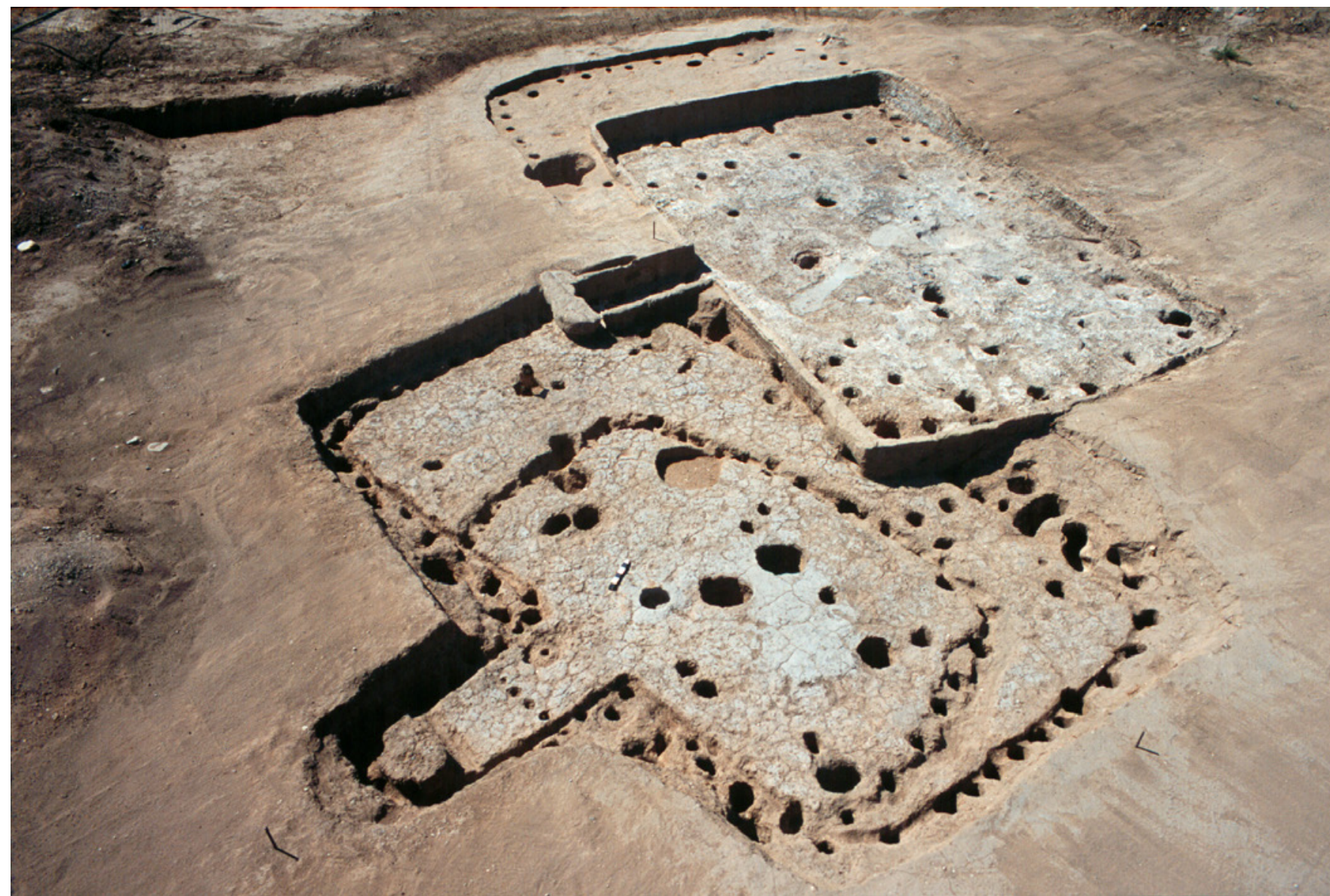

FIGURE 1. This image of overlapping features was printed $3^{\prime} \times 6^{\prime}$ and used on several virtual site tours. Photo by Carol J. Ellick.

is a good idea to discuss the inclusion of public tours of the site with your company's insurance representative. I've developed and led hundreds of tours (without incident) on CRM projects, and the insurance policies covered the programs.

If safety and accessibility are too much of an issue, you can bring the site to the public. Create a virtual site tour using large format images or video footage. This could be posted on the project website, the client's website, on a blog, or presented as a slide show.

Creative Solution: Virtual Tour, an Alternative to an On-Site Tour. Virtual (non-computer) tours for professional archaeologists in workshops always surprise people. At first, seeing a person in a field hat and holding a clipboard might seem funny. The participants look at the photos of the archaeological features spread around on the floor of the room and attempt not to laugh. Then the tour begins: "Welcome to the archaeological site. I'd like to thank our sponsors... Before we get started, there are some basic rules I'd like to cover..." The "visitors" fall into their roles, asking the same sorts of questions that are asked on-site.

Preparation takes forethought, but the process is fairly easy. High-resolution digital photos of the features to be highlighted, taken from the appropriate location where you would stand if giving a site tour, set the stage. Prepare the handouts and props (see below for more details). Using a plotter printer, print $3^{\prime} \times 5^{\prime}$ feature photos (Figure 1). At the venue, arrange the images on the floor, patterned as they would be on-site, and then conduct the tour. If you want, you can even warn people to stand back from the edge of the feature so that it doesn't cave in under them.

\section{Security}

Site security is something archaeologists all worry about, although typically we advocate that education and outreach are a good security measure. In all the years that I've been leading site tours, I've never recognized an incident where someone came on the tour to scope out what could be stolen at a later time. Of course, certain precautions were taken-the area was fenced, features were not left open after hours, artifacts were removed before work was completed for the day, and the names and contact information for everyone who came to the site were collected and maintained.

Creative Solution: Junior Site Stewards. On a site located in southwest Tucson, the entire fifth grade of the neighborhood elementary school (with their parents) became site stewards. These students were taught about archaeology and cultural history, trained on observation skills, and taught not to approach anyone or enter the site on their own. They walked by the site 
on the way to and from school. They walked their dogs by the site and were asked to contact us if anything looked out of place or if they saw suspicious activity on-site. This site was in their community and they wanted to protect it.

\section{PRE-TOUR PREPARATION}

Pre-tour preparation includes selecting the appropriate personnel and setting up the on-the-ground logistics. The personnel should include the public outreach specialist to develop and run the program and a support staff including a clerical assistant and a graphic artist. The clerical assistant will help with organizing, registering people for tours, distributing information, and ensuring that everything is in its place when needed. He or she will also help document the day's events at the conclusion of the tours. The graphic artist will produce the props used on the tour, the banner, display, handouts, and any additional visuals needed to advertise the tours.

\section{The Public Outreach Specialist}

Leading tours requires an ability to organize, plan, develop and maintain a schedule; analyze information; create a verbal story; develop visual aids; communicate with a diverse audience; have an understanding of the archaeological process and culture being investigated; and have a sparkling or at least an outgoing personality. This is not an entry-level crew position. It is also not a position to give to your usual archaeologists, many of whom "by nature prefer the company of a scorpion in the bottom of their unit to facing an expectant audience" (Ellick 2002:9).

Tour guides weave the people, human lives, and lifestyles back into existence. Communication skills are essential. As Larry Zimmerman (2003:11) notes, "We deal with the material results of cultural norms. We are forced to objectify, and that often takes the 'humanity' out of our work." The role of the tour guide is to make what we do understandable to those who are not in the profession. Tour guides need to avoid using archaeological jargon, and when it is required, be able to explain what every term means in a way that an educated layperson can understand.

A tour guide should also have training or experience in archaeological fieldwork and laboratory processing of cultural materials; knowledge of local culture history and chronology of the region; knowledge of environmental changes through time; experience working with local communities; and education or experience in cultural communication and educational theory.

\section{Logistics}

Preparation for tours should begin several weeks prior to the onset of the tours themselves. The outreach specialist should become familiar with the cultural and environmental history of the area, not just by studying the archaeological record but also by speaking with contemporary local groups and descendant populations. In this way, public outreach will have a broader social impact, such as the impact had by the projects identified in Archaeologists and Local Communities: Partners in Exploring the Past (Derry and Malloy 2003) and Archaeology, Heritage and Civic Engagement: Working toward the Public Good (Little and Shackel 2014).
In addition to building community relationships, logistics during this phase of the project should include purchasing the materials for the greeting area and props. Advertising venues should be researched and approved by the client, and on-site arrangements should be made for parking and the tour assembly area.

\section{Public Relations and Registration}

Control of access to the site requires that tours should be by advance registration only. Some agencies prefer that their contract officer control all media contact. With the advent of social networking and email, getting the word out about site tours has become easier, but don't rely only on these venues. Send information to local schools. Contact the local PBS station about posting tours on their community calendar or about having a segment on a local TV magazine or newscast (Figures 2 and 3). Keep the science writer for your local paper informed as the project proceeds.

Use available resources. The American Anthropological Association (2016) has a developed a tipsheet for writing press releases that can be quite helpful, and Larry Zimmerman (2003) provides an entire chapter entitled "Media Method or Media Madness" that can help.

\section{Parking}

Create a designated parking area. If smoking on the site is prohibited, post a notice on the outside of the fence stating, "No Smoking Beyond this Point." (You can explain the potential for contamination of carbon 14 samples during your talk.)

\section{Greeting Area}

Hang a large banner with the site or project name and contact information by the entry to the site or at a practical staging area. The greeting area should include a canopy; six-foot tables for the display, guestbook, and handouts; a water cooler and paper cups; first aid kit; some chairs; and a trashcan (Figure 4).

The tabletop display provides information that supports the tour, but doesn't cover identical information. It provides an opportunity to expand on the limited information presented on the tour by placing the site in a broader context and by helping to bring in community and descendant perspectives and voices.

The display can also provide additional information about archaeology, including definitions of words frequently used on the site and acronyms. Any artifacts displayed should be theft resistant. The exhibit should thank the project sponsors and acknowledge their interest in going beyond contract requirements by providing tours as a public benefit of the project.

As an additional resource, consider recommending reliable websites for more information and offering brochures, Archaeology Month information, or membership flyers from the local avocational society so that visitors have something to take home.

\section{Weaving the Story}

Before creating the narrative, you have to create a story in your mind about the place, one that goes beyond features and artifacts - the dry bits of scientific data and material culture-and 


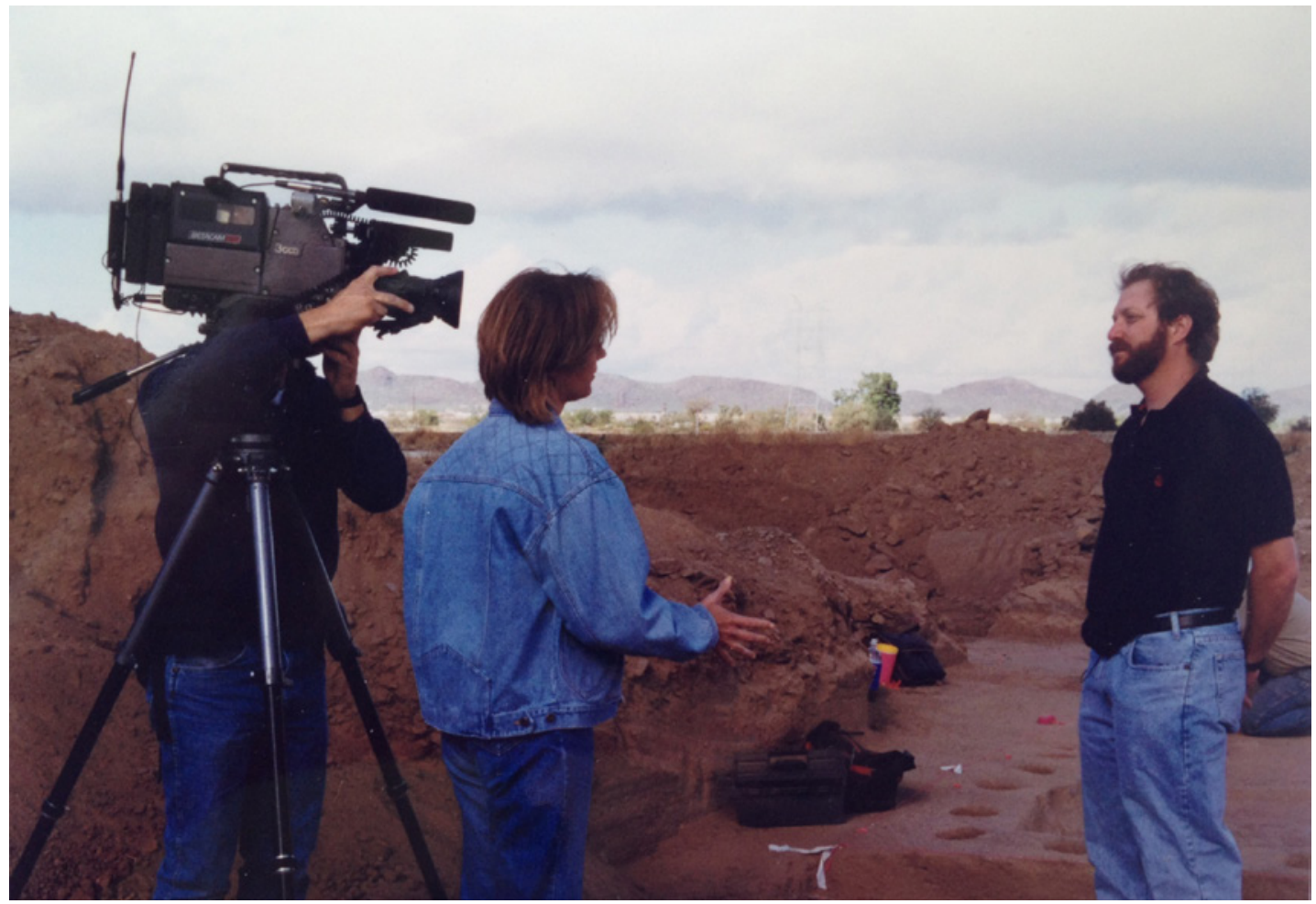

FIGURE 2. Jeffrey H. Altschul, Statistical Research, Inc., being interviewed by a Tucson television news reporter. Photo by Carol J. Ellick.

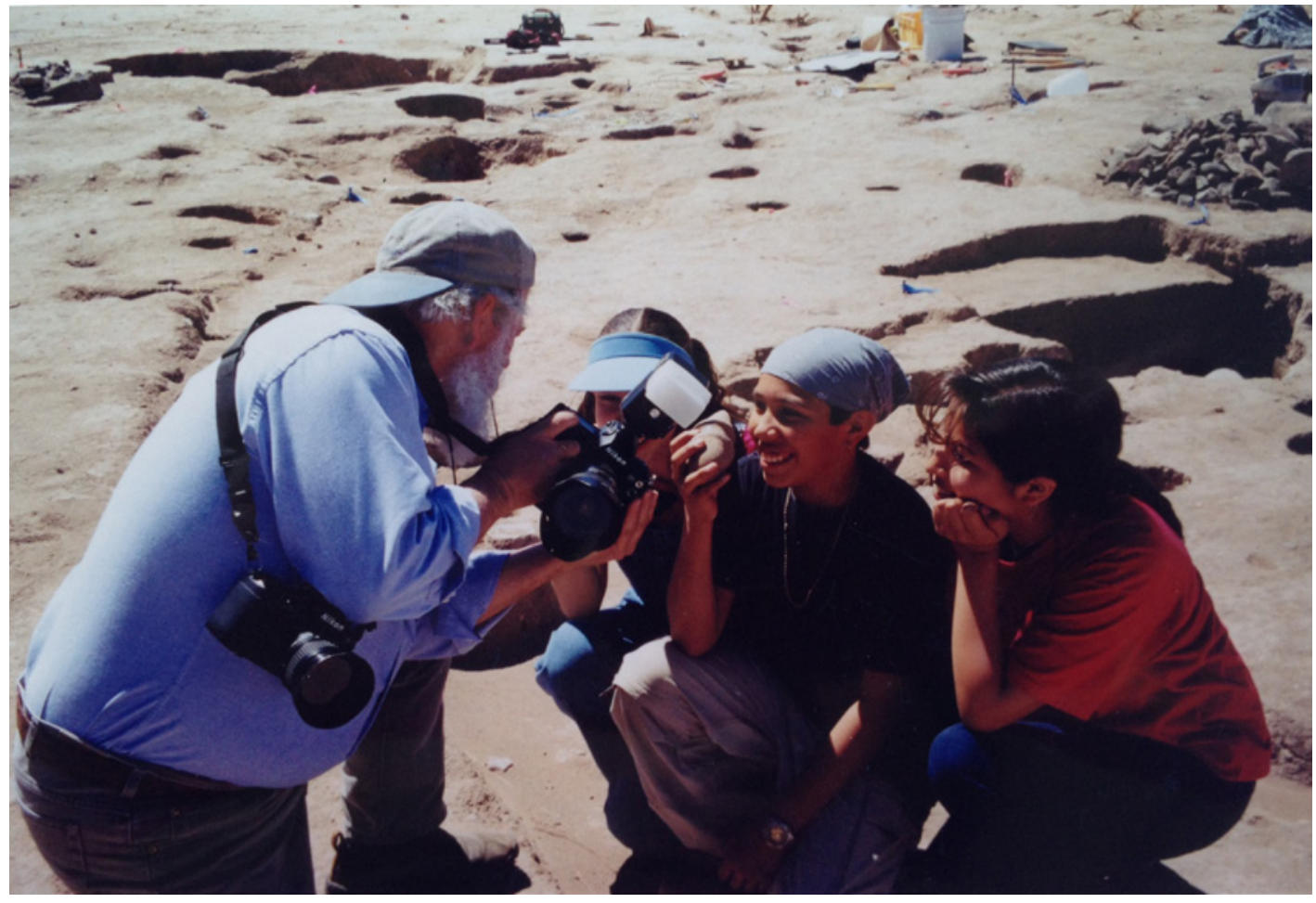

FIGURE 3. Two students from the Tohono O'odham Nation look at the image on the screen of a digital camera of a photographer from a Tucson newspaper. Photo by Carol J. Ellick. 


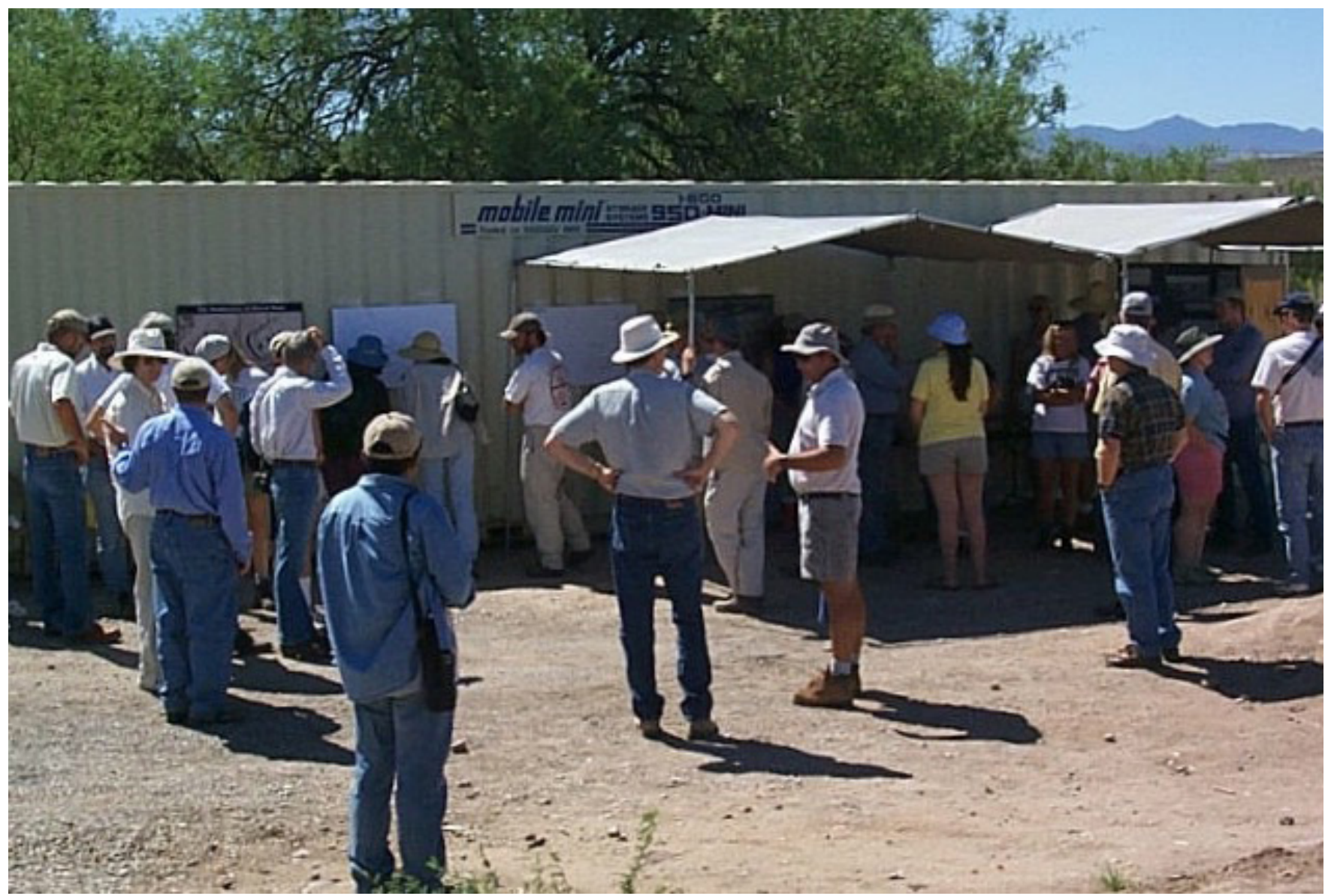

FIGURE 4. A group gathered at the meet-and-greet area on the Marsh Station Archaeological Project. In addition to the three-panel display on the table at the end of the covered area, the walls of the "Mobile Mini" storage shed were used to hang additional visuals. Photo by Carol J. Ellick.

puts them into the daily activities of human lives. This mental image provides the backdrop for the short narrative that you give within the tour.

Relate a site and features to what is familiar to the visitor so that they have a base on which to build new knowledge. For example, ask the group, "If I walked into your bedroom, from the objects, would I be able to tell if it was occupied by a female or male? By more than one person? Would I be able to tell if you liked sports? Were messy or clean?" This information can be easily correlated to the archaeological process of trying to understand who lived here and why based on what they've left behind.

In developing the story about the site, consider the following questions: What is the story being told? What ethics are going to be woven into the presentation? How can people be educated not to pick up artifacts when they find them? How can knowing about the past help us understand the present and help affect the future?

All of these things should be worked out before entering the field. There is a limited time to make the point. "Master the sound bite" (Zimmerman 2003:130). Find the hook and reel in your audience.

\section{Create the Tour Narrative}

What questions are the archaeologists at the site trying to answer? Who was here, when, why, what were they doing, and what is the relationship of this site to others in the region? Although there would be some overlap between questions one might ask to create a narrative for any archaeological site, the following questions were developed for creating the narrative for tours on a pre-contact site.

- Why is this site here? Is it located in a pass between hills? Perhaps it is set along a transportation corridor that controlled trade to the east and west, where even today there is a railway and an interstate.

- What were people doing here? Was this a major village site? Did people travel here from afar to trade, celebrate, and meet future husbands and wives? Was it a specialty site where people focused on a particular "craft" such as making pottery?

- How does this site relate to the larger scheme? This site does not stand alone in a vacuum; it is part of a larger network. Where are the hunting sites, the gathering 
sites, the farming sites, and the major social gathering sites?

- How old is the site? What was happening in the world at this time? How do you know how old the site is? What are relative and absolute dating?

- Is the site believed to be ancestral to any modern peoples? If so, it may be helpful to refer to their memories, oral histories, or legends about the people who occupied the site.

Humanize the data. The culture being "created" is more than the "piles of sherds, reams of computer printouts, and office cubicles" used to write the site reports (Ellick 2000:190). In the technical reports, everything has to be quantified, but when presenting the story to the public, weave a story and make it believable based on the evidence at hand. The audience will be diverse, with little or no archaeological background. It will be important to build that base of knowledge.

In developing the narrative, consider whether the story of the place differs from the accepted history of the area. Correlating prior understandings, how histories are documented, and how new discoveries are integrated can help build a fuller picture that may help debunk myths or provide supportive evidence to broaden the story beyond one told from a singular cultural perspective. But it's important to consider time limits. It's impossible to squeeze the entire cultural sequence and its relationship to this site into 30 minutes. Keep it simple, keep it interesting, and keep it moving.

\section{Tour Route}

Designate a path using stakes and flagging tape or barricade fencing through the site to avoid injuries and to protect the site and its features from damage. Use shade panels to keep sensitive materials from full view, such as burials or features that some cultural group may wish to have shielded. Select stopping points that can accommodate the whole tour group, so that the group faces you when you stop with the feature behind or next to you.

Creative Solution: Take a "Cheat Sheet." Tell the story about who lived here, what they were doing, and how they used the resources based on the archaeological evidence and traditional cultural stories from the "script" that has been developed. If there is a particularly complex set of overlapping features, like house floors, keep a "cheat sheet," such as the one illustrated in Figure 5, with the information, as well as important dates to supplement the reconstruction drawings of houses that are shared with visitors.

Talk to the project director and crew every morning before tours begin to find out if any new information has emerged. Consider using diagnostic artifacts found on previous days to show at corresponding features. Doing this keeps the tour fresh and shows how the story of the site is built.

\section{Create Props}

Visualizing what a feature looked like during use based on a verbal description and a series of holes in the ground is difficult. The use of drawings can help. Signboards can be created as simple line drawings, printed on 8.5" $\times 11^{\prime \prime}$ paper and mounted on foam core with spray adhesive. Figures 6, 7, and 8 are props that were used on the Marsh Station (Mescal Wash) Archaeological Site tours. The three figures were shown at the corresponding on-site features.

\section{TOURS ("READY...SET...GO!")}

The tour in the example is scheduled to be 30 minutes long, with 10 minutes for questions. This plan allows tours to begin on the hour and stay on track. Before the official tours start, try doing some dry run-throughs with field personnel or people from the office.

\section{Tour Day}

Before beginning the tour, ask everyone to sign the guest book. Gather the group. Keep the visitors comfortable and make sure they are able to see what is being discussed by keeping the sun at their backs. Welcome people, introduce yourself, and thank the project sponsors. Describe the process for the tour and define the safety rules. Tell people that, while the excavation area looks stable, the archaeologists are digging in dirt. If people stand too close to the edge, it will collapse into the pit, potentially injuring the visitor, the crew member, and destroying part of the site.

You will also want to explain any other site-specific safety concerns. For example, explain that the site is mapped using a grid and that the corners of the grid are marked with rebar or stakes that can cause serious injury if accidently walked into or fallen on. Explain why the excavations are being done and the fact that they are entering an active archaeological investigation. Ask them not to pick up or touch anything seen along the tour, since these materials may or may not have been mapped yet and their position relative to everything on the site is important. Also tell them that the time allowed for the tour is limited and you want to show and explain to them as many things as possible, so they need to stay together as a group while walking from one place to the next. Keep the introduction short. Save any site-specific information for when you are actually on the path overlooking the site or by the features (Figures 9 and 10).

During the tour, wait until everyone has reached the information point before you begin talking. If someone asks what people are doing in a sensitive area, stop and explain in general terms why it is being avoided.

Back at the entry/exit, provide time for the visitors to look at the display and pick up handouts. Ask them to write comments in the guestbook. Once they are gone, get set to do it again. Where possible, conduct debriefing sessions with the field crew at various times throughout the tour season. This can be helpful for identifying issues or concerns that they might have or for eliciting additional information for inclusion on tours. 


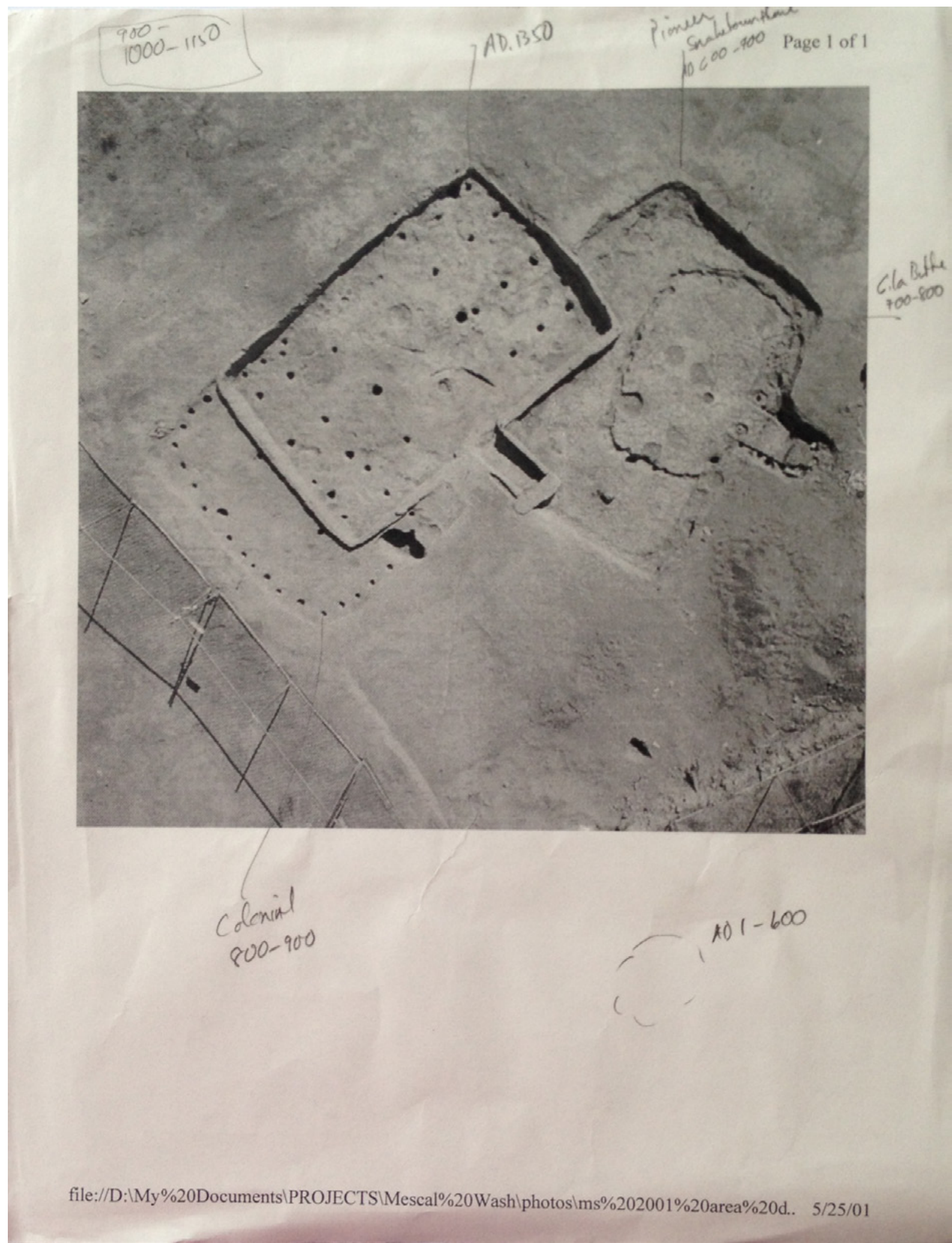

FIGURE 5. This printed photo page was carried on the Marsh Station site tours and referenced for dates and time periods of the overlapping features. Photo by Carol J. Ellick. 


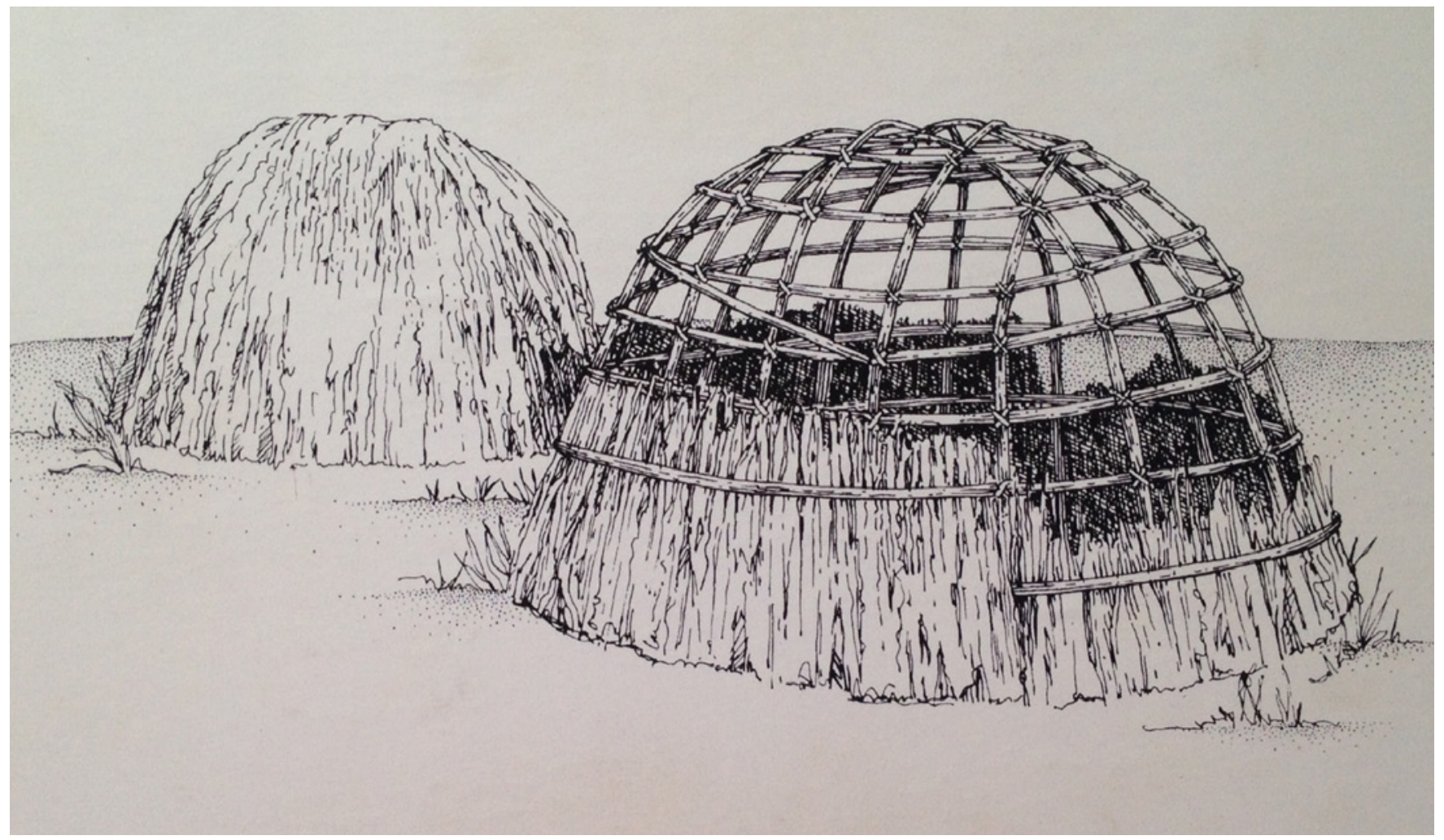

FIGURE 6. Reconstruction drawing of a brush structure dating to the Archaic period. The front structure is unfinished, providing the audience a glimpse of the construction method. Illustration by Carol J. Ellick.

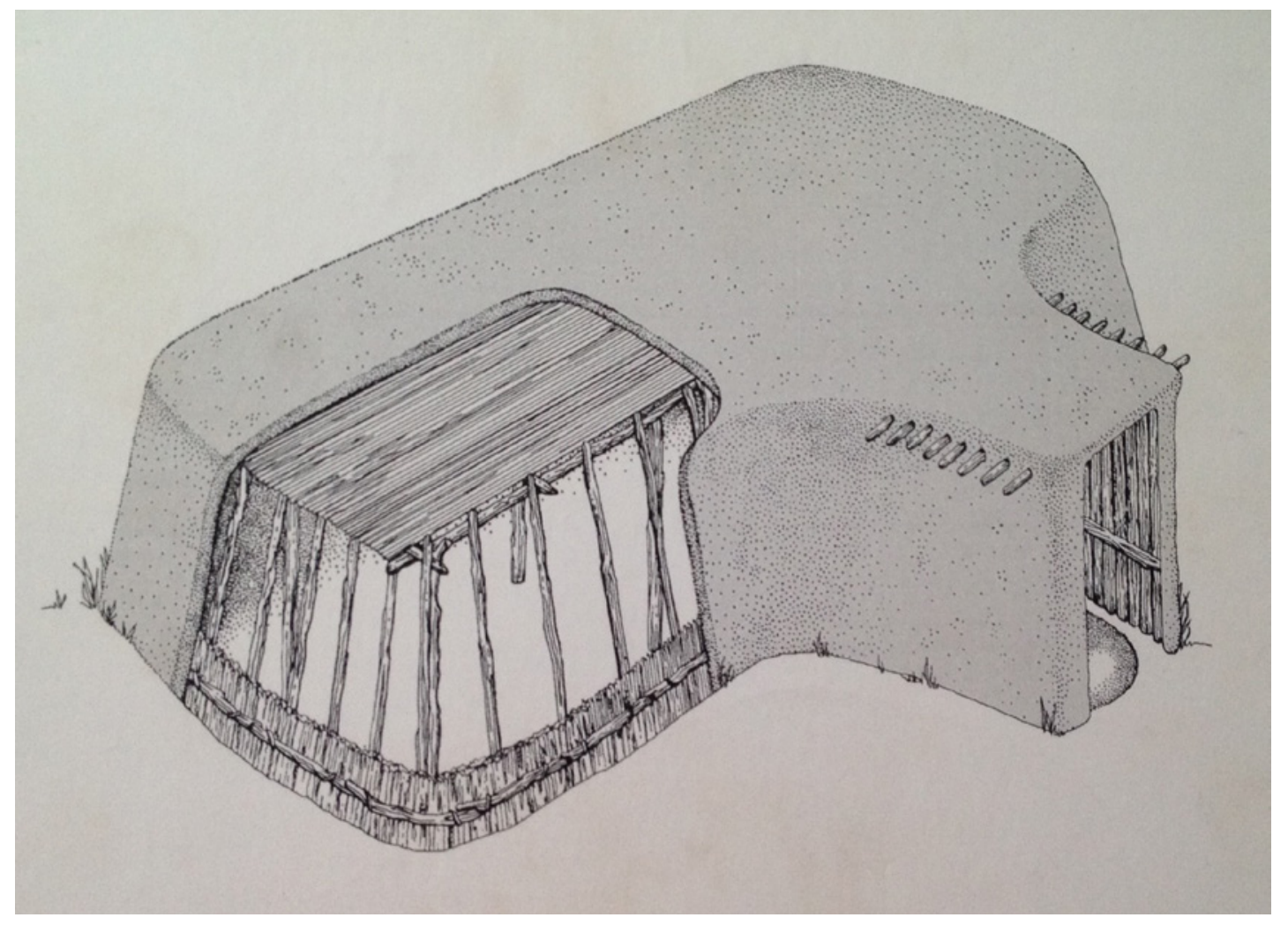

FIGURE 7. Reconstruction drawing of a Hohokam pit structure. Illustration by Cynthia Elsner. 


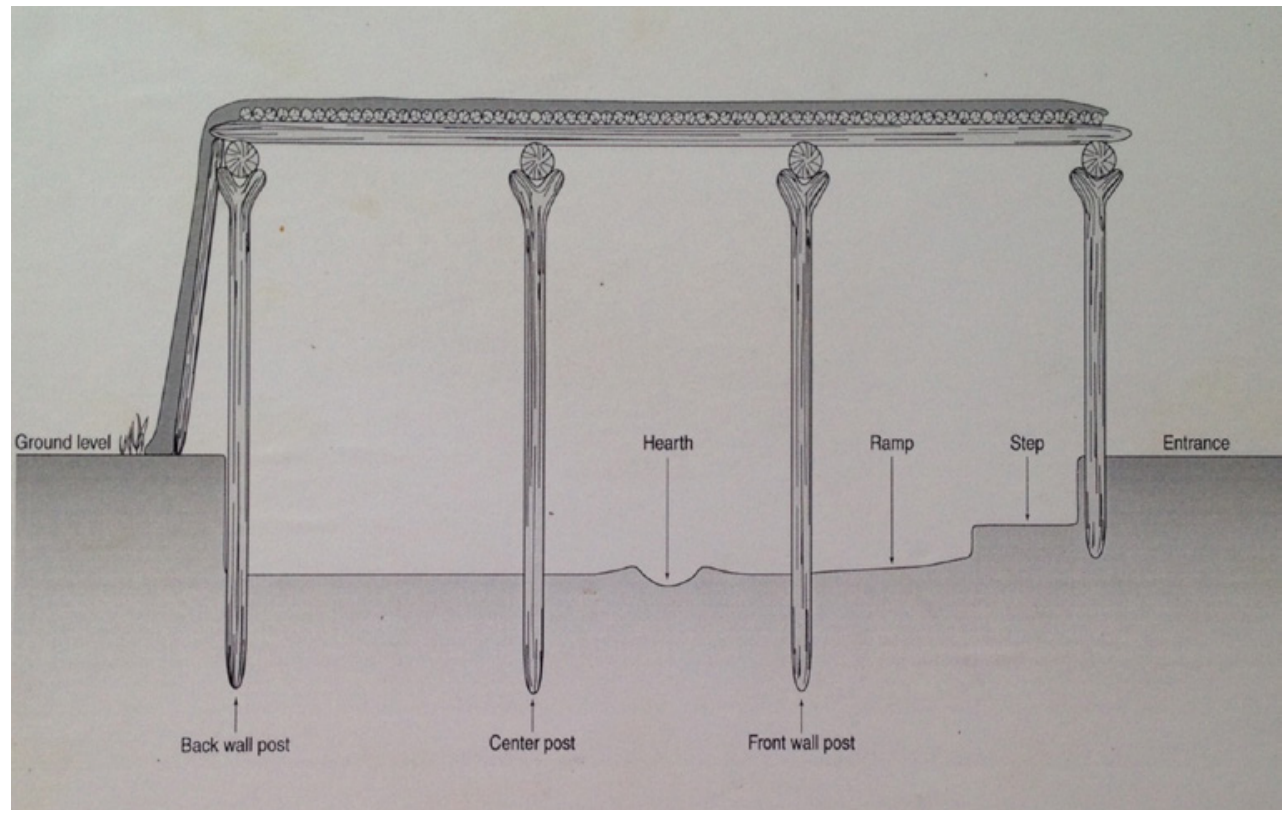

FIGURE 8. The interior construction of a pit structure illustrating post holes and construction techniques. Illustration by Cynthia Elsner.

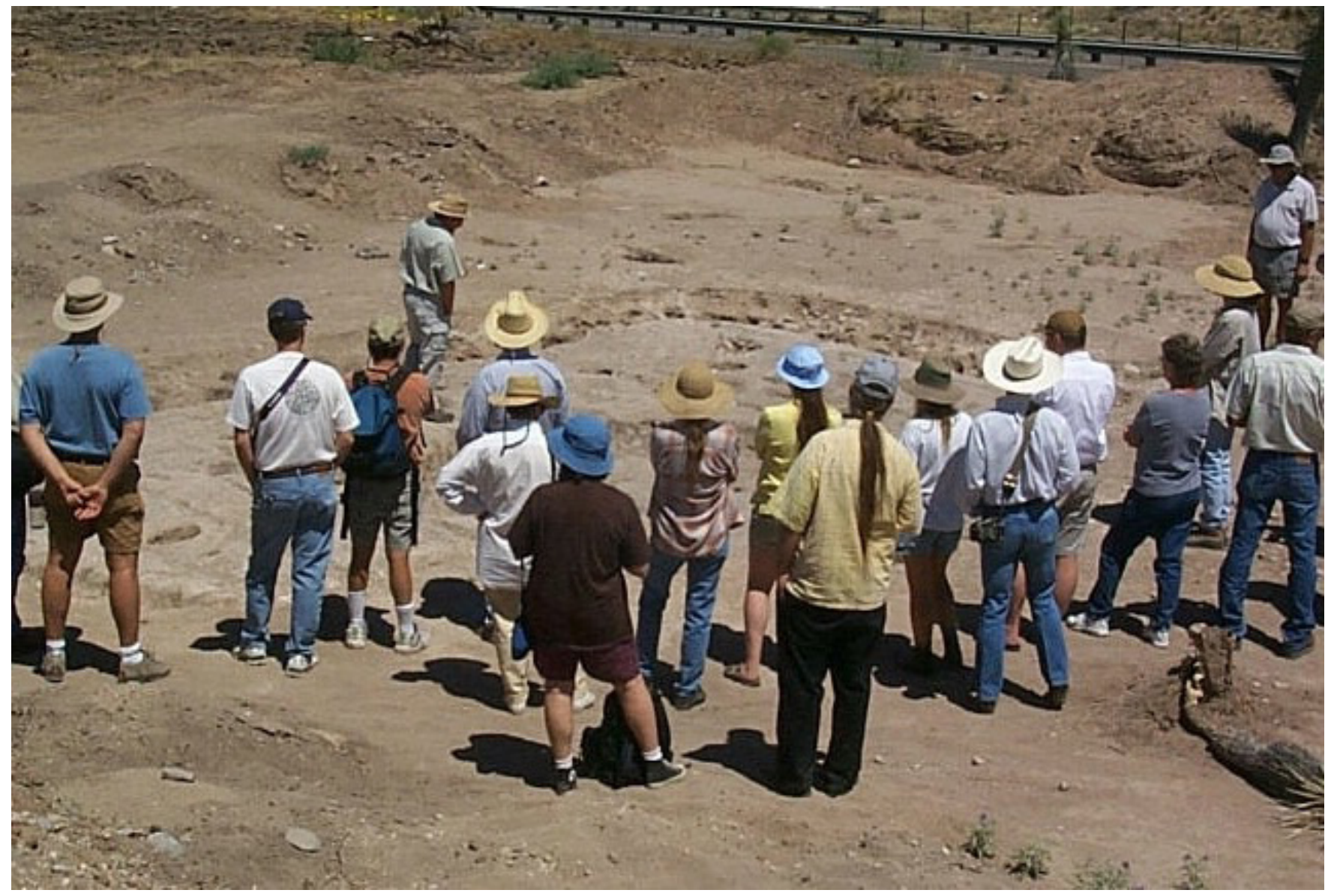

FIGURE 9. Professional archaeologists on a site tour during the Information Sharing Meeting at the Marsh Station Archaeological Site. Photo by Carol J. Ellick. 


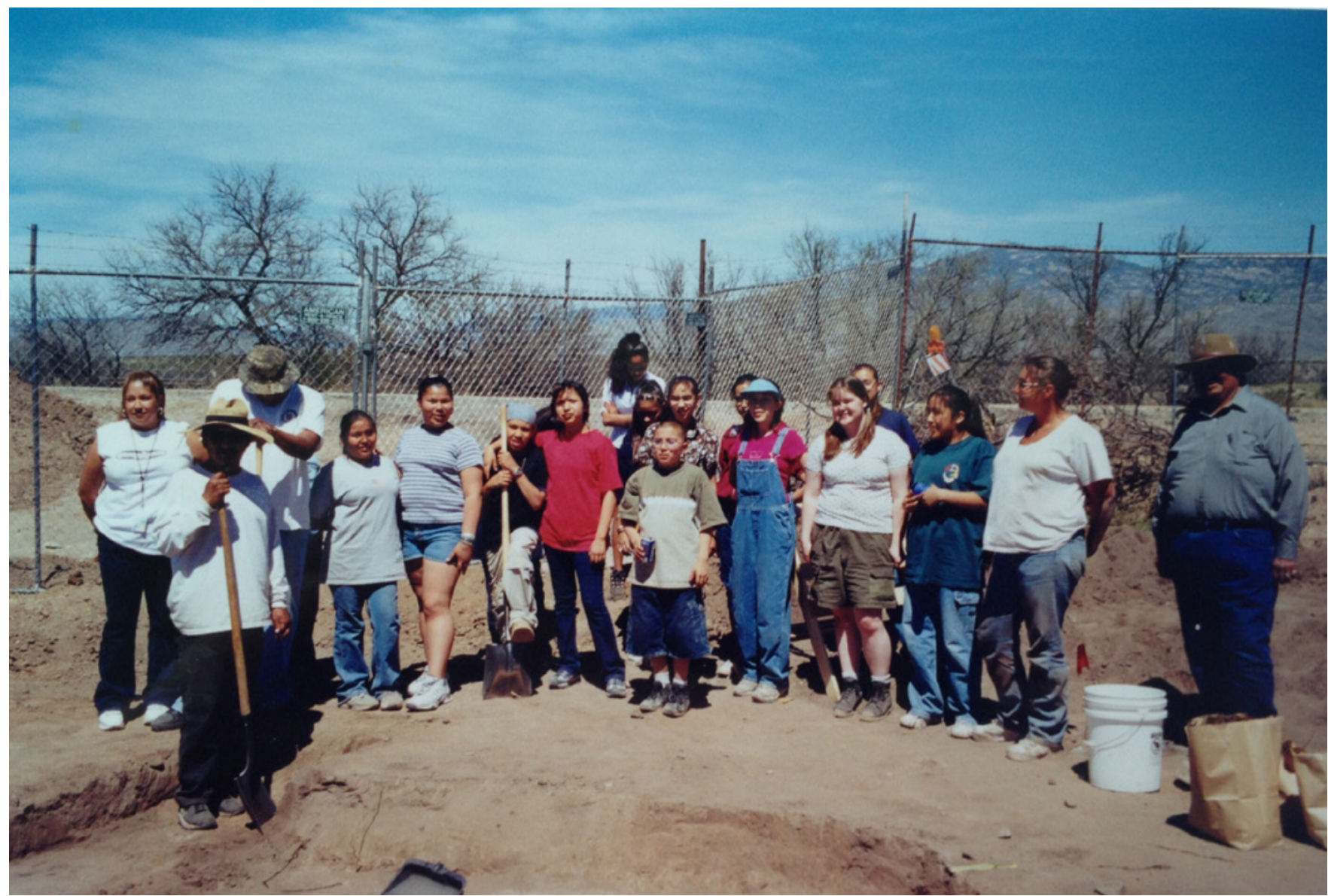

FIGURE 10. A special tour of the Marsh Station Archaeological Site was arranged for the American Indian Studies class at Challenger Middle School, Tucson, Arizona. Photo by Carol J. Ellick.

\section{FOLLOW-UP}

The site tour program should be written up and included in the final documentation of the work. Prepare a table listing the total number of people who participated in the site tour, as well as representative comments. The guestbook, thank you notes, and follow-up materials should all be submitted to the contract officer, with a letter report summarizing the outreach efforts.

\section{CONCLUSION}

There are lots of excuses for not doing public outreach—money, time, safety, security-but most of these problems can be surmounted with preplanning and coordinated communication. Not doing outreach is easy, but it is our ethical, and in many cases, our legal responsibility to share our findings with the public. Following a process for developing and hosting tours in appropriate situations takes preparation and the right person, but once you start doing it, finding ways to include it becomes easier and easier. From a public relations perspective, providing site tours brings in positive comments for the client, builds community understanding of archaeology and cultural history, and reinforces the need to preserve archaeological sites. More importantly, site tours help to create a public who can better understand what archaeology can tell us about ourselves, and who can also become stewards of past places.

\section{Data Availability Statement}

No physical or digital data were used in the production of this manuscript, with the exception of electronic documents, which appear as online publications.

\section{REFERENCES}

American Anthropological Association

2016 Writing Press Releases. Electronic document, http://www. americananthro.org/Staylnformed/Content.aspx?|temNumber $=1632$, accessed December 14, 2015

Derry, Linda, and Maureen Malloy

2003 Archaeologists and Local Communities: Partners in Exploring the Past. Society for American Archaeology, Washington, D.C.

Ellick, Carol J

2012 A Line Item in the Budget. Paper presented at the SAA Meetings, Memphis, Tennessee.

2002 Don't Forget the Cookies and the Fruit. The SAA Archaeological Record, 2(2):8-10 


\section{HOW-TO SERIES}

2000 Against the Clock. In The Archaeology Education Handbook, edited by Karolyn Smartz and Shelley J. Smith, pp. 183-191. AltaMira Press,

Walnut Creek, California.

Little, Barbara J., and Paul A. Shackel

2014 Archaeology, Heritage, and Civic Engagement: Working toward the Public Good. Left Coast Press, Walnut Creek, California.

National Historic Preservation Act

1966 National Historic Preservation Act of 1966, as amended. Electronic document, http://www.achp.gov/docs/nhpa\%202008-final.pdf, accessed December 14, 2015.

Secretary of the Interior

1983 Secretary of the Interior's Standards for Archeological Documentation. Electronic document, http://www.cr.nps.gov/local-law/arch_stnds_7.htm, accessed December 14, 2015.
Zimmerman, Larry J.

2003 Archaeologist's Toolkit 7: Presenting the Past. AltaMira Press, Lanham, Maryland.

\section{AUTHOR INFORMATION}

Carol J. Ellick Archaeological and Cultural Education Consultants, PO Box 11115, Takoma Park, MD 20913 (cjellick@theaceconsultants.com) 